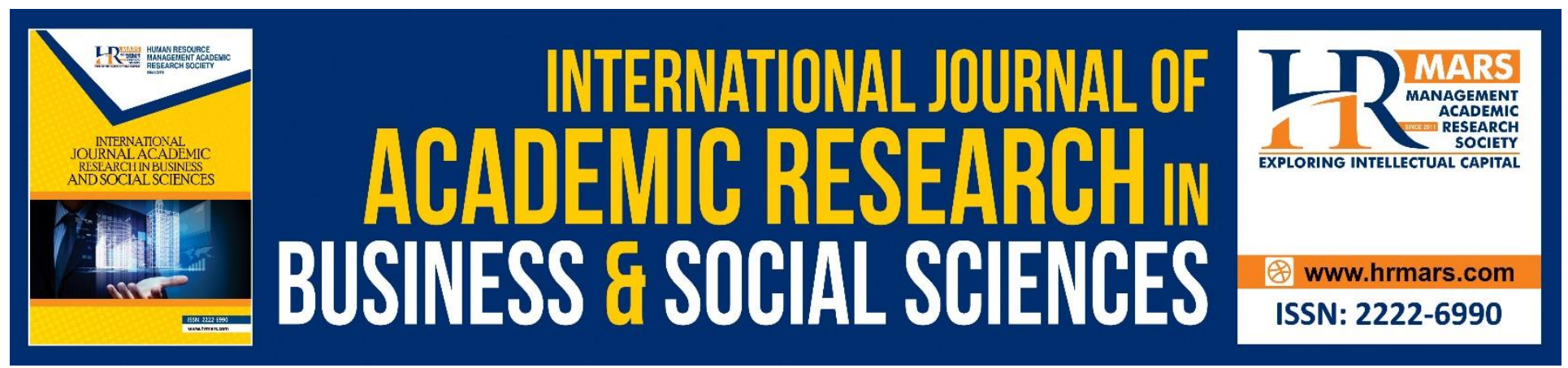

\title{
Mediating Effect of Uncertainty on The Relationship Between Interpersonal Attraction Traits and Life Happiness amongst Facebook Users
}

Jusang Bolong, Sri Azra Attan

To Link this Article: http://dx.doi.org/10.6007/IJARBSS/v10-i15/8248

DOI:10.6007/IJARBSS/v10-i15/8248

Received: 13 September 2020, Revised: 14 October 2020, Accepted: 11 November 2020

Published Online: 26 November 2020

In-Text Citation: (Bolong \& Attan, 2020)

To Cite this Article: Bolong, J., \& Attan, S. A. (2020). Mediating Effect of Uncertainty on The Relationship Between Interpersonal Attraction Traits and Life Happiness amongst Facebook Users. International Journal of Academic Research in Business and Social Sciences, 10(15), 267-283.

Copyright: (C) 2020 The Author(s)

Published by Human Resource Management Academic Research Society (www.hrmars.com)

This article is published under the Creative Commons Attribution (CC BY 4.0) license. Anyone may reproduce, distribute, translate and create derivative works of this article (for both commercial and non-commercial purposes), subject to full attribution to the original publication and authors. The full terms of this license may be seen

at: http://creativecommons.org/licences/by/4.0/legalcode

Special Issue: Youth and Community Wellbeing: Issues, Challenges and Opportunities for Empowerment V1, 2020, Pg. 267 - 283 http://hrmars.com/index.php/pages/detail/IJARBSS JOURNAL HOMEPAGE

Full Terms \& Conditions of access and use can be found at http://hrmars.com/index.php/pages/detail/publication-ethics 


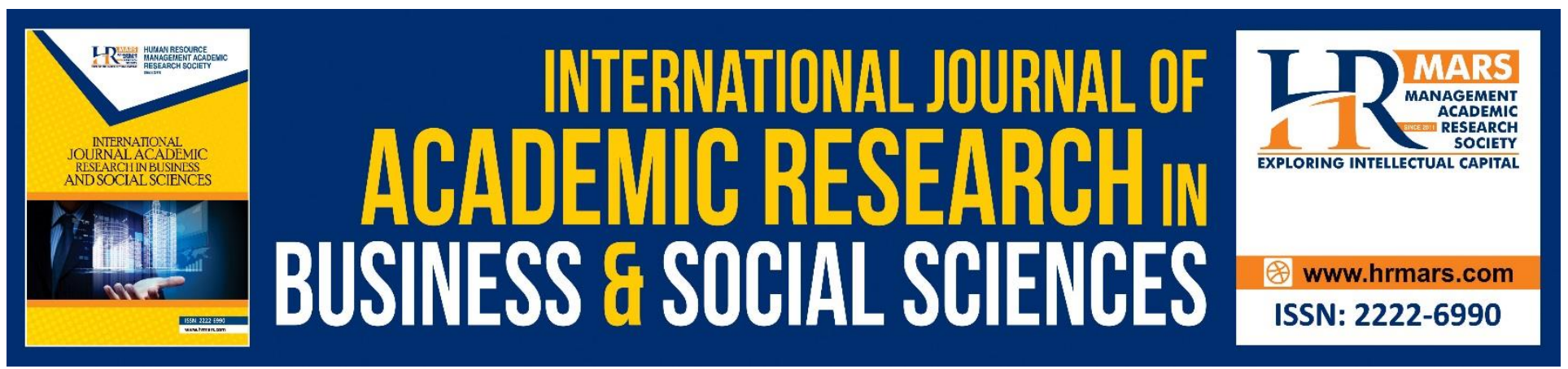

\title{
Mediating Effect of Uncertainty on The Relationship Between Interpersonal Attraction Traits and Life Happiness amongst Facebook Users
}

\author{
Jusang Bolong ${ }^{1,2}$, Sri Azra Attan² \\ ${ }^{1}$ Institute for Social Science Studies (IPSAS), Universiti Putra Malaysia, \\ 43400 UPM Serdang, Selangor, Malaysia, ${ }^{2}$ Faculty of Modern Languages and Communication, \\ Universiti Putra Malaysia, 43400 UPM Serdang, Selangor, Malaysia. \\ Email: jusang@upm.edu.my
}

\begin{abstract}
There is a large amount of uncertainty that needs to be assured for experiencing happiness in life since interpersonal attraction judgments are promptly developed during initial interactions. Thus, the objective of this study was to examine the mediating effect of uncertainty on the relationship between interpersonal attraction traits and life happiness amongst Facebook users. This study was using an integrated purposive sampling method through a snowballing procedure by considering the characteristics of respondents to suit the purpose of the study. A total of 503 questionnaires were distributed online, with only 402 respondents returned the questionnaire. It is found that there is a mediating effect of uncertainty on the relationship between interpersonal attraction traits and life happiness amongst Facebook users, namely physical attraction, social attraction, and extraversion. This study proposes the combination of the analytical unit for interpersonal attraction traits and life happiness by integrating the variable measurements in multiple contexts of social media platforms.

Keywords: Uncertainty, Interpersonal Attraction Traits, Life Happiness, Facebook, Mediated Communication
\end{abstract}

\section{Introduction}

Research has suggested that improving life happiness leads to numerous benefits. As life is more fulfilling by enhancing happiness, life happiness is associated with health improvement, decision making development, better work performance, and productivity growth (Zelenski et al., 2008). A happier society is a more supportive society since individuals in a higher level of life happiness are more positive and helpful toward others (Fredrickson, 2003).

Conversely, people in a situation of depression and extremely low in life happiness tend to commit suicide (Daly \& Wilson, 2009). People who suffer from the feeling of unhappiness in life are expected 
to be involved in deviant behaviors (Markova, 2018), e.g., alcoholism or crime, and engage in work withdrawal behaviors, e.g., workers are gossiping instead of working (Sharkawi, Rahim, \& Dahalan, 2013).

However, all those life happiness magnitudes stated happened in Face-to-Face (FtF) interaction. It was found that enhancing life happiness by utilizing the Internet can overcome the feeling of loneliness (Amichai \& Artzi, 2003). Given that social support is fundamental for happiness, an online social connection is competent for boosting self-esteem (Huang et al., 2015), enhancing happiness in life.

Prior research on MC use encountered that the lack of life happiness caused adverse psychological outcomes in cyberspace, e.g., narcissism, cyberbullying, neuroticism, low self-esteem, loneliness, and antisocial behavior; e.g., delinquency, aggression, and depression (Park, 2014). There were also linkages between $\mathrm{MC}$ and the need for life happiness, which were directed to negative feelings, e.g., substance addiction, boredom, irritation, and attention-deficit, e.g., low concentration, hyperactivity, and learning disabilities (Williams et al., 2011).

Essentially, the research of the negative impacts of social media, for instance, Internet addiction, anxiety, jealousy, and its implication on human communications, is part of the sphere for researchers to be addressed (Clayton et al., 2013). Generally, excessive Facebook usage creates conflict, which associates with adverse relationship outcomes that make it possible for considering broader research on the relational consequences of more significant time spent on Facebook use (Kerkhof et al., 2011). Although the use of social media can complicate the aspects of a relationship for some, it can also ease a relationship for others (Hertlein \& Webster, 2008). Thus, research indicated that social media, like Facebook, could enhance happiness in people's lives by communicating positive content rather than harmful matters (Bazarova et al., 2015). Given that Facebook is known to inspire happiness, life happiness could be managed by reading news and updates through Facebook (Suwanphrom, 2016).

Seeing that interpersonal relationship is a vital source of life happiness, it can be achieved apparently through initial relationship (Sprecher et al., 2013). In this case, the initial relationship is governed by interpersonal attraction, mainly through social media, as it has become a life routine for many people. However, few researchers have discussed the interpersonal attraction traits through MC. When scholars investigated the relationships in new media transformation, they only focused on how social media affects relationships and the use of social media in relationships (Kashian et al., 2017). Previous research has shown that interpersonal attraction traits were able to improve happiness by focusing on the predictors of life happiness; e.g., physical attraction (Sneade \& Furnham, 2016), social attraction (Edwards \& Harris, 2016), task attraction (Woo \& Jungryum, 2016), sexual attraction (Wolfe \& Patterson, 2017), similarity (Human \& Biesanz, 2011), extraversion (Agbo \& Ngwu, 2017), and popularity (Wang et al., 2017).

Since interpersonal attraction judgments are promptly developed during initial interactions, there is a large amount of uncertainty that needs to be assured of experiencing happiness in life (Zhang \& Ji, 2003). Previous studies documented that interpersonal attraction and uncertainty are negatively 
related (Horan, 2016). Even though people are happier if the level of interpersonal attraction is getting higher (Berrios et al., 2015), the feeling of happiness still depends on the uncertainty about the opposite person, whether it is definite or vice versa (Flesher, 2015). Thus, uncertainty is a significant issue between them, considering that it is the essence of happiness in life.

In brief, there are earlier studies about the relationship between interpersonal attraction and life happiness, e.g., Mrad and Cui (2017); Hall (2016); Bakkenbull \& Kiefer (2015); Scott (2014); Winter et al. (2011); Antheunis \& Schouten (2011). However, the limitation is that the scholars were only focusing on the direct effect of interpersonal attraction to life happiness. Whereas from the theoretical perspective, they are supposed to consider a mediating role in determining the strengths and weaknesses of associations between interpersonal attraction and life happiness. Thus, there is an inadequacy of knowledge in their studies, where it should be a mediating variable to strengthen the relationship between interpersonal attraction and life happiness.

Uncertainty has not been investigated comprehensively in an MC situation, as it is always associated with FtF interactions (Sheldon, 2009). This issue makes interpersonal attraction in cyberspace more challenging than the FtF environment since $\mathrm{MC}^{\prime}$ 's characteristics provide advanced alteration for selfdisclosure (Heisler \& Crabill, 2006). Hence, it takes a longer time to treasure enough information for users to be attracted to each other to develop online relationships because of adjournment and interruption. For instance, the delayed character caused by the duration of typing, waiting for responses, and replying messages that provide users with the opportunity to revise, improve or revoke their messages, and statements before the transmission of information (Scheibe \& Gupta, 2017).

Although social media expands the human social reach (Horrigan et al., 2006) by enabling long-distance communications, and time constraint is not the matter, there is still a deficiency in physical and social cues through MC. For instance, direct video and audio occurrences like in FtF interaction and MC users could not develop a relationship with others as fast as in $\mathrm{FtF}$ due to the barrier of communication.

Life happiness refers to the individual's state of affairs who successfully manage time well and succeed in achieving balance in their whole life through daily activities from various aspects, including work, family, health, and social relations (Gropel, 2005). Life happiness is the psychological state of well-being, joy, and contentment, which evolved from the positive movement in life (Lyubomirsky, 2001) since the pursuit of happiness is an important life goal for every human being (Gray et al., 2017).

Peterson et al. (2005) proposed an Orientations to Happiness (OTH) to meet the destination of happiness through pleasure, engagement, and meaning; towards the path between full and empty life. Likewise, people are happier if they are sure about the information of a person they needed to know (Garrison \& Lee, 2017). Within the context of this study, uncertainty would be tested whether it mediates the relationship between interpersonal attraction traits to enhance happiness in life or vice versa. However, the OTH does not confer the element of uncertainty in determining three different orientations, namely pleasure, engagement, and meaning of life. 
Thereupon, Media Richness Theory (MRT) refers to the situations, which demand the information exchange for uncertainty reduction. It regards the media that can transmit needed information for uncertainty reduction and ambiguity resolution to achieve the goal of communication (Spiegelhalter, 2017). Within the context of this study, information may transmit via photo and video-sharing in social media, such as Facebook or Instagram.

Graham et al. (2017) stated that a person who hungers for happiness should undergo several factors in reducing uncertainty to enhance their happiness in life. Thus, several tasks require communication skills for uncertainty reduction as a solution for the problems arise, such as the authenticity of information delivered. Thus, the MRT is based on whether there is uncertainty in a state; thus, different media communication methods should be applied according to their richness levels. However, the communication approach to handle the situation depends on the richness level of media involved. Although the MRT attached the explanation for uncertainty reduction, it did not touch on which view may be interrelated with interpersonal attraction.

The concept of interpersonal attraction traits relates to Interaction Appearance Theory (IAT), which presented that interpersonal attraction perceptions are varying before and after the interaction; this depends on whether the interactions are positive or negative ones. The IAT proposed that effective communication leads to increased perceptions of attractiveness and pursuing a new relationship, even when initial levels of attractiveness were low (Pena \& Brody, 2014).

The IAT suggested that the pictures of interpersonal attraction are changing from positive to negative perceptions if irritative interaction between communicators is kept on going (Dix, 2013). Although the first impression and perception are created upon the first engagement, the interpersonal attraction is still depending on the quality of interaction between communicator, whether they have a valuable communication with excellent communication skills and proper attitude or vice versa.

Maintaining social relationships has been defined as a core element of aging well. With a considerable amount of older adults living alone, social media provides the possibility to engage in meaningful social contact, e.g., by joining online social networks, e.g., Facebook (Leist, 2013). Geographical distance to kin, impaired mobility, or time-consuming obligations such as caregiving may hinder older adults from satisfying the need for social contact, with the risk that these adults feel lonely but have little opportunity to engage in social contact. Social media, especially Facebook, can provide older adults with empowerment, a construct that refers to a global sense of connectedness and increased control and self-efficacy (Barak et al., 2008), which involves the effects of interpersonal relationships and social processes. Thus, it seems promising to engage users in online support groups.

Society nowadays has been breached by the emergence of Internet-based social media, which became a substitute medium to foster relationships amongst others regardless of the age factor. Thus, could MC be the platform for enhancing happiness in life? Is it possible that the interpersonal attraction occurs directly through MC? These questions are raised due to growing concern that FtF interaction is more gratifying socially and emotionally rather than MC condition (Lundy \& Drouin, 2016). 
Although MC offers an alternative for people who are in the situation of isolation and loneliness to improve their life happiness, they still have the intention to publish unconstructive and destructive contents on the Internet, compared to those who are with companions, which negatively affected their level of happiness in life (Jin, 2013). Thus, the objective of this study was to examine the mediating effect of uncertainty on the relationship between interpersonal attraction traits and life happiness amongst Facebook users.

\section{Methodology Data Collection}

The data collection for this study was executed through a quantitative approach by using a surveydevelopment website, specifically http://bit.ly/2w4QXEd. The users of Facebook were chosen as the primary target population since Facebook is the world's largest and most popular online Social Networking Sites (SNS) (Mohammadi et al., 2020).

A non-probability sampling technique was implemented to generate a sample size for this study. It is difficult to identify the population in this study due to the rapid growth of New Communication Technology. Thus, this study was using an integrated purposive sampling method through a snowballing procedure by considering the characteristics of respondents to suit the purpose of the study. This procedure includes asking people who have contributed to a survey to recommend other people they assume are attached to the research and willing to participate in the survey. Later, the sampling carried on until the required number of responses is achieved.

Within this study context, the relevant Facebook feature in structuring the snowballing procedure is a Facebook group. Thus, a researcher created the Facebook group based on specific interests, including the attraction to one specific local friend in the first year of involvement on Facebook, based on the initial relationship period is between 1-3 years (Baumeister \& Vohs, 2007). A snowballing procedure was then initiated by gathering respondents to one Facebook group via links to selected Facebook friends. Since the group administrator has access to control the content and the membership of the group, the administrator then progressively transmitted a message to up until the maximum of 5,000 group members. A total of 503 questionnaires were distributed through online, with only 402 respondents returned the questionnaire.

\section{Profile of Facebook Users}

Within the context of this study, female users were more likely to use Facebook compared to male users. The majority of Facebook users in this study are dominated by the digital-savvy generation, namely Gen-X and Gen-Y. Apart from that, single users were spending more time on Facebook, compared to married users. This result is driven by the occurrence that someone who uses Facebook multiple times per day gets about half the boost in total support that someone receives from being married or living with a partner (Hampton et al., 2011). Malay users dominated Facebook compared to other races, followed by Chinese, Indian, and other races, namely Iban, Kadazan, Murut, and Bidayuh. This outcome is due to Malaysia as a multicultural country that established many races in its population, with the Malays constitute the majority of the population in Malaysia. Simultaneously, the Chinese and Indians are the significant minority within the total population (Crouch, 2019). 
Malaysian Muslim users were using Facebook more, followed by Buddhists, Hindus, and Christians. It is important to note that in terms of religion aspect, Islam is the most widely practiced religion in Malaysia, with almost 62\% of the population being Muslims (Azzman \& Manaf, 2019). The majority of Facebook users in this study were students, followed by users who served in the private sector and the government servant. However, the minority ran their own business in various fields such as restaurant, laundry, and cyber cafe, while some were housewives and jobless. Almost half of Facebook users in this study were using Facebook at home, followed by at work, while others were using Facebook at cafes, libraries, faculties, colleges, and hostels. Only the minority of them were paying for the service at a cyber cafe.

\section{Measurement}

Physical attraction is measured through an instrument from the Interpersonal Attraction Scale (IAS) by McCroskey and McCain (1974). Initially, the IAS response set was using a five-point Likert scale ranging from 1 for strongly disagree to 5 for strongly agree. Within the context of this study, it was not altered, implemented from the original scale to maintain the scaling slope. Ten physical attraction items by utilizing a five-point Likert scale of ordinal data. The Cronbach's (1951) alpha reliability for the IAS response set ranged from the lower 0.70s to the upper 0.90s in most previous studies.

Social attraction is also measured through an instrument from IAS constructed by McCroskey and McCain (1974), which uses a five-point Likert scale, ranging from 1 for strongly disagree to 5 for strongly agree. Ten social attraction's items by utilizing a five-point Likert scale of ordinal data. The reliability of Cronbach's (1951) alpha values for the IAS have ranged from the lower 0.70s to the upper $0.90 \mathrm{~s}$ in most of the previous studies.

Extraversion is measured through The Eysenck Personality Questionnaire-Revised (EPQR) response set by Eysenck \& Eysenck (1994), which uses a five-point Likert scale ranging from 1 for strongly disagree to 5 for strongly agree. The EPQR is known in measuring extraversion with the average of Cronbach's (1951) alpha values is above 0.8 for each item around the world; such as England, Canada, United States of America, and Australia (Francis, Brown, \& Philipchalk, 1992), which ranged from the lower 0.70 s to the upper 0.90 s in most of the previous studies.

The measurement of popularity was adapted from Facebook Popularity Scale (FPS) by Zywica \& Danowski (2008) as self-report measures to assess the popularity on Facebook. FPS primarily consists of six items that were created to measure online self-reported popularity. However, only three out of six items were selected to represent popularity on Facebook. Another six items of popularity were adapted from the Popularity Scale (PS) by Santor et al. (2000) as a self-report measure to assess the popularity among younger adolescents. All the popularity items on FPS were using a five-point Likerttype response with the closed-ended questions. The answer choices ranged from 1 for very unpopular, 2 for unpopular, 3 for neutral, 4 for popular, and 5 for very popular. The five-point scale was not amended, utilized from the initial scale to maintain the scaling slope, except the scale description was changed to give more understanding to the respondents. According to Zywica \& Danowski (2008), all the FPS's items were checked for reliability by computing the Cronbach's (1951) 
alpha values, and the overall reliability for Facebook popularity had a coefficient of 0.78 and ranged from the lower 0.70 s to the upper 0.80 s in most of the previous studies.

The measurement of uncertainty was adapted from the Clatterbuck Uncertainty Evaluation Scale (CLUES) by Clatterbuck (1979), the prominent instrument in research on determining interpersonal uncertainty. The CLUES assess the respondents' self-confidence in predicting the other person's emotions, feelings, attitudes, and behavior. This seven-item questionnaire was designed to measure an individual's general level of uncertainty toward other people. However, the assessing approach of the CLUES focused on the interpersonal attraction in FtF communication solely. Therefore, within this study's context, the initial measurement was adapted to suit the applicability of online study, on Facebook particularly; for example, all items for this variable were added "...on Facebook." at the end of every sentence. Overall, no reverse items were introduced by the CLUES.

The life happiness measurement was adapted from the Orientations to Happiness (OTH), designed by Peterson et al. (2005) as self-report measures. Thus, the initial measurement was adapted to suit the online study's applicability, particularly on Facebook, e.g., all items in this section were added "After my involvement on Facebook ..." in front of every sentence. Within this study's context, out of 36 items of Orientations to Happiness (OTH) measurement, only 29 items were selected to represent life happiness due to the suitability and applicability of online study, especially on Facebook. Even more, 11 negatively worded items were reverse coded.

\section{Findings and Discussion}

People are happy when uncertainty is decreased, due to Facebook users always shows their physical attraction.

Based on Table 1, the relationship between physical attraction and life happiness is mediated by uncertainty amongst Facebook users. As other Facebook user shows more physical attraction, the lower the uncertainty, the higher the life happiness. The finding is consistent with Wu \& Zheng (2019) that people nowadays were posting photographs on the Internet to display their physical appearance, and to highlight their uniqueness and attractiveness (Tifferet \& Vilnai-Yavetz, 2014), in order to present an idealized image of themselves and to share the positive aspects of their lives. This assertion is wired by Pounders et al. (2016) that users who posted selfies were motived to express happiness through their physical appearance. Therefore, other users who catch the glimpse will be affected by the positive vibes and sense the happiness through bliss and joyfulness in their life. Besides, Tiedens and Linton (2001) suggested that happiness in life, leading to more thinking to reduce uncertainty, which notably found that uncertainty avoidance predicts happiness significantly (Steel \& Ones, 2002). However, this idyllic representations evoked a sense of uncertainty, which triggered the emotion of curiosity that spoiled over the psychological well-being (Alfasi, 2019). For that reason, once physical attraction occurred through photos or videos on Facebook, happiness is enhanced as soon as the uncertainty is reduced. This claim is due to people cannot just hardly think about anything else if they are uncertain about an important outcome because they do not know which outcome to make sense of and explain (Gambetta, 2000). Since uncertainty includes assumptions of many (Scott, 2014), people are uncertain about the person that they are physically 
attracted to and attempted to lower their uncertainty about that person. Subsequently, the uncertainty reduction resulted in the enhancement of happiness in their life.

Facebook users who always shows social attraction will make people happy, provided that the uncertainty about them is reduced significantly.

This study also discovered that the relationship between social attraction and life happiness is mediated by uncertainty amongst Facebook users. Hence, as other Facebook user shows more social attraction, the lower the uncertainty, the higher the life happiness. This outcome is congruent with Hancock, Toma, \& Fenner (2008) that people judge attractiveness not only based on one's profile photograph but also based on others' comments on Facebook. Hong et al. (2012) tightened the finding of this study that people with Facebook profile photos, which include social cues, were perceived to be more socially attractive than people with profile photos that were plain headshots. The photos posted without any caption or explanation will only escalate uncertainty, making other users speculate about the real circumstances of a person. In the end, Facebook users whose profile photos include social cues, additional information about the user, and many positive comments on their profile photos are viewed much more socially attractive than users who have fewer social cues and negative comments on their profile photos. During the process of reducing uncertainty, the information seeker creates mental models that help him/her to make sense of other people; and their intentions, emotions, and behaviors (Antheunis et al., 2010). The result also shows that social attraction can improve life happiness, that people are cheerier and happier by only receiving more messages from friends through comments on Facebook (Burke \& Kraut, 2016). While receiving personalized and effortful communication through social interaction on Facebook, it was linked to the enhancement of life happiness.

As other Facebook user shows more extraversion, the lower the uncertainty, the higher the life happiness.

There is also a mediating effect of uncertainty on the relationship between extraversion and life happiness amongst Facebook users. As other Facebook user shows more extraversion, the lower the uncertainty, the higher the life happiness. This outcome strengthened the finding of Darbyshire et al. (2016) that people's status updates reflect their personality information. Just like in real life, extraverts socialize more on social media; they upload photos, use the "like" button and update their status more frequently than introverts (Lee et al., 2014). Despite this routine activity that is pleasing and delighting to users who follow his daily progress, the sense of happiness will be increased if uncertainty is reduced, since uncertainty is often unbearable experiences that people try to avoid at all costs (Bauman \& May, 2019). In cue-poorer Mediated-Communication (MC), users develop skills to decode textual cues, e.g., language errors and emoticons, and to reduce uncertainty about a target person (Hu et al., 2004). This strategy to reduce uncertainty is used to gain information about a target person in initial interactions. By initial interactions, it means the entry phase during which interactants experience uncertainty and a lack of predictability about their new relational partner (Neuliep \& Grohskopf, 2000). Due to extraversion characteristics, which are positive emotionality, sociability, and dynamic behavior, lower uncertainty is associated with increased feelings of happiness and fewer depressive symptoms (Cheng \& Furnham, 2003). 
Uncertainty can be reduced if other Facebook user always shows their popularity, and this makes people much happier (Figure 1). However, the uncertainty did not mediate the relationship between popularity and life happiness amongst Facebook users. This result concludes, as other Facebook user shows more popularity, the lower the uncertainty, the higher the life happiness. This signifies that as more popularity is shown by other Facebook users, the lower the uncertainty, it is, however, not enhancing life happiness. This event is probably due to the characteristics of extraversion and social attraction that seem to be more welcoming with responsiveness and friendly oriented (Ranjbartabar et al., 2019) compared to the physical attraction that is just an overview of immense persona in the Facebook community (Robards, 2014). Even though popularity embodied experience tied to positive feelings (Goodwin et al., 2016), it does not mean that reducing the uncertainty would enhance the life happiness amongst Facebook users. This fact is probably due to Facebook profile owners' popularity was associated with larger networks (Feiler \& Kleinbaum, 2015), that enhanced socializing and often linked to social events, which keeps them always in the bustle and do not have enough time to respond to every user who is attracted to them. This situation creates frustration amongst other Facebook users, and the life happiness enhancement is not able to be continued, although the uncertainty regarding the person that they are attracted to is reduced.

Figure 1 and Table 1 show the findings of mediation analysis regarding the relationship between interpersonal attraction traits, uncertainty, and life happiness amongst Facebook users, which also explained the decision of hypothesis testing.

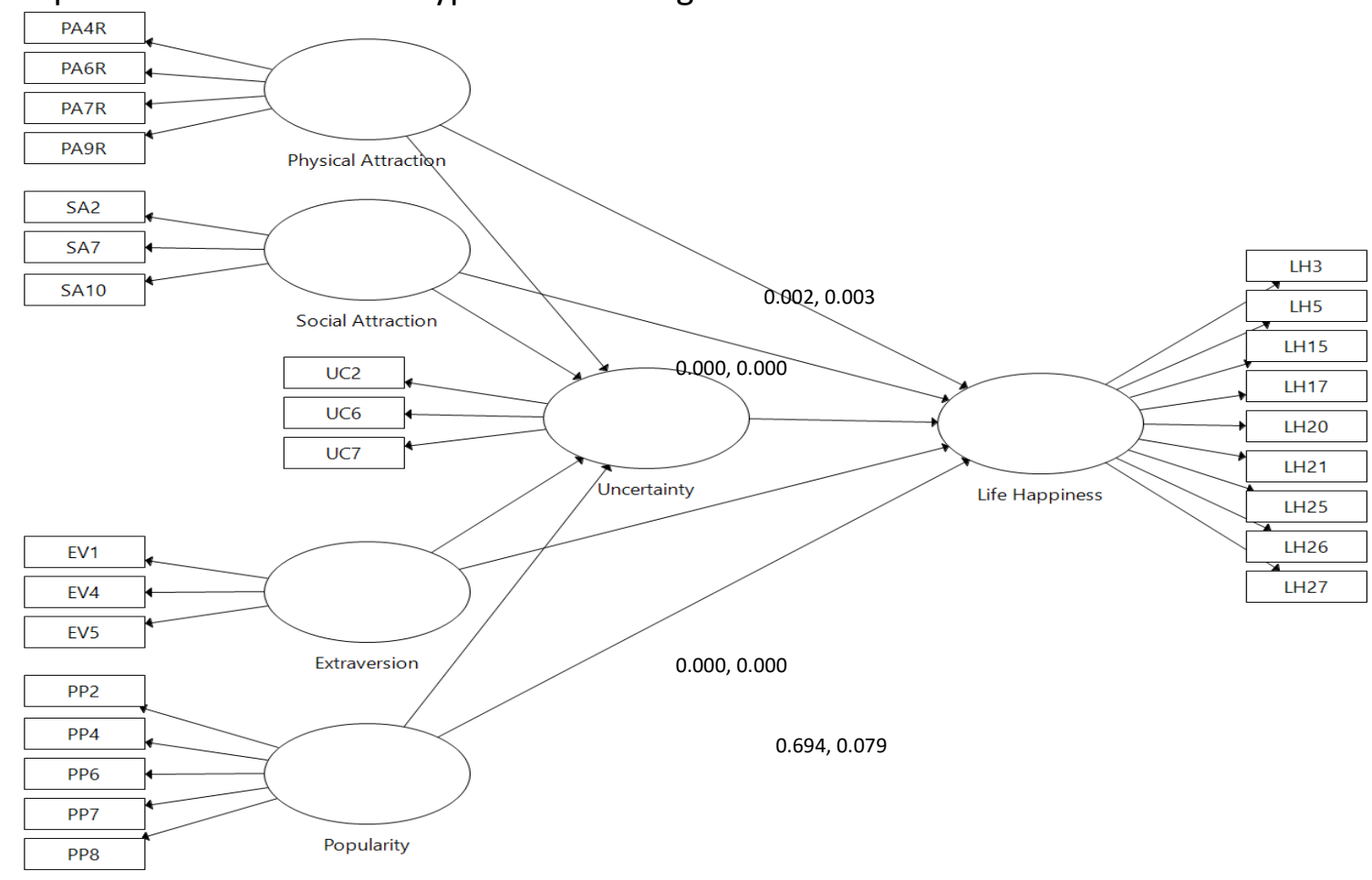

Figure 1: Mediating Effect of Uncertainty on the Relationship between Interpersonal Attraction Traits and Life Happiness amongst Facebook users ( $\mathrm{N}=402)$ 
INTERNATIONAL JOURNAL OF ACADEMIC RESEARCH IN BUSINESS AND SOCIAL SCIENCES

Vol. 10, No. 15, Youth and Community Wellbeing: Issues, Challenges and Opportunities for Empowerment V1. 2020, E-ISSN: 2222-6990 @ 2020 HRMARS

Table 1: Mediating Effect of Uncertainty on the Relationship between Interpersonal Attraction Traits and Life Happiness amongst Facebook users ( $N=402)$

\begin{tabular}{|c|c|c|c|c|c|}
\hline Assumptions & Construct & $\begin{array}{l}\text { Direct } \\
\text { Effect }\end{array}$ & $\begin{array}{l}\text { Indirect } \\
\text { Effect }\end{array}$ & Mediation & Decision \\
\hline $\begin{array}{l}\text { People are happy when the uncertainty } \\
\text { is reduced, due to Facebook users } \\
\text { always shows their physical attraction. }\end{array}$ & $\begin{array}{l}P A \rightarrow U C \\
\rightarrow L H\end{array}$ & 0.002 & 0.003 & Yes & Accepted \\
\hline $\begin{array}{l}\text { Facebook users who always shows } \\
\text { social attraction will make people } \\
\text { happy, provided that the uncertainty about } \\
\text { them } \\
\text { is reduced significantly. }\end{array}$ & $\begin{array}{l}\mathrm{SA} \rightarrow \mathrm{UC} \\
\rightarrow \mathrm{LH}\end{array}$ & 0.000 & 0.000 & Yes & Accepted \\
\hline $\begin{array}{l}\text { As other Facebook user shows more } \\
\text { extraversion; the lower the uncertainty, } \\
\text { the higher the life happiness. }\end{array}$ & $\begin{array}{l}\mathrm{EV} \rightarrow \mathrm{UC} \\
\rightarrow \mathrm{LH}\end{array}$ & 0.000 & 0.000 & Yes & Accepted \\
\hline $\begin{array}{l}\text { Uncertainty can be reduced if other } \\
\text { Facebook user always shows their } \\
\text { popularity, and this makes people } \\
\text { much happier. }\end{array}$ & $\begin{array}{l}\mathrm{PP} \rightarrow \mathrm{UC} \\
\rightarrow \mathrm{LH}\end{array}$ & 0.694 & 0.079 & No & Rejected \\
\hline
\end{tabular}

\section{Life Happiness Predictive Model through Facebook}

Based on the structural model evaluation through SmartPLS, the effect size $\left(f^{2}\right)$, predictive accuracy $\left(R^{2}\right)$, and predictive relevance $\left(Q^{2}\right)$ analysis illustrate the factors that contribute to the predictor of life happiness. Since the effect size assesses the strength of the relationship between the latent variables, it means that the bigger the effect size, the more strength of the relationship between the latent variables occurs (Wong, 2013).

On that account, based on Table 2 , the $\mathrm{f}^{2}$ value of extraversion for predictive accuracy of life

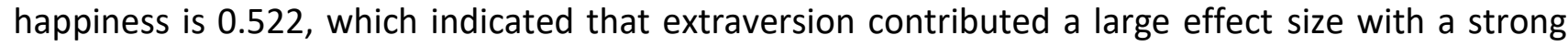
relationship in producing the predictive accuracy of life happiness. Besides, the finding also explains that the $f^{2}$ value of social attraction for predictive accuracy of life happiness is 0.250 , which signifies that social attraction contributed a medium effect size with a moderate strength of relationship to predict the accuracy of life happiness amongst Facebook users. Meanwhile, 0.025 is the $f^{2}$ value of physical attraction; and the $\mathrm{f}^{2}$ value of popularity is 0.100 ; for the predictive accuracy of life happiness. Thus, this analysis indicated that physical attraction and popularity had only poured a small effect size, which produced a weak relationship towards the predictive accuracy of life happiness amongst Facebook users.

In other quarters, the cut-point values of predictive accuracy $\left(R^{2}\right)$ produced the precise prediction of life happiness. Therefore, based on Table 2 , the $R^{2}$ value of uncertainty is 0.588 , which suggested that the accuracy of uncertainty prediction is moderate. This result implies that $58.8 \%$ variance of 
uncertainty is explained by interpersonal attraction traits, precisely physical attraction, social attraction, extraversion, and popularity. Meanwhile, the $\mathrm{R}^{2}$ value of life happiness is high, as the predictive accuracy is 0.785 , which indicated that $78.5 \%$ variance of life happiness is explained by interpersonal attraction traits, namely physical attraction, social attraction, extraversion, and popularity altogether.

Table 2: Life Happiness Predictive Model through Facebook ( $N=402$ )

\begin{tabular}{llll}
\hline Structural Constructs & $\mathbf{f}^{\mathbf{2}}$ & $\mathbf{R}^{\mathbf{2}}$ & $\mathbf{Q}^{\mathbf{2}}$ \\
\hline Physical Attraction & 0.025 & & \\
Social Attraction & 0.250 & & \\
Extraversion & 0.522 & & \\
Popularity & 0.100 & & \\
Uncertainty & 0.040 & 0.588 & 0.290 \\
Life Happiness & & 0.785 & 0.521 \\
\hline \hline
\end{tabular}

As a summary, $\mathrm{f}^{2}, \mathrm{R}^{2}$, and $\mathrm{Q}^{2}$ indicated that the values are well reconstructed and that the model has predictive accuracy and predictive relevance.

Notwithstanding, the Life Happiness Predictive Model through Facebook must be able to predict the endogenous latent variable through the Stone-Geisser's $\left(Q^{2}\right)$ value. Therefore, as shown in Table 2, the $Q^{2}$ value of uncertainty is 0.290 , which defines that the model with uncertainty is relevant at a moderate level. Meanwhile, life happiness's predictive relevance is decidedly relevant, as the $Q^{2}$ value of life happiness is 0.521 , which indicated that the Life Happiness Predictive Model through Facebook is highly relevant. For further details, Table 2 shows the $f^{2}, R^{2}$, and $Q^{2}$ values of a structural model in this study.

\section{Conclusion}

Out of four factors that should produce the direct effects on life happiness, there are only three significant factors to be the contributors towards life happiness amongst Facebook users, namely, physical attraction, social attraction, and extraversion. However, since uncertainty is particularly important in SNS usage, it is necessary to examine the uncertainty as the mediating variable in this study. As a result, it is found that there is a mediating effect of uncertainty on the relationship between interpersonal attraction traits and life happiness amongst Facebook users. Therefore, those three factors are more significant to be the contributors to life happiness when the uncertainty is reduced.

Consequently, people must have the traits of extravert in order to be happy by using technology in the cyberspace. This is due to the extraverted person is happier in life compared to a physically attractive person and a socially attractive person. In this case, an extraverted person must always be surrounded by people and always be in the center of attraction in order for them to be happy in the cyberspace. In contrast, if an extraverted person keeps isolating themselves on Facebook, they will sense the feeling of unhappiness in life. Although the usage of Facebook depends on the traits of an extraverted person; however if the uncertainty is still high about the person that they were attracted 
to, they still cannot feel the happiness in their life, which will lead to negative feelings such as depression, anxiety, low self-esteem, and aggression. Therefore, this study recommended a model that can be used in the psychological sight to predict the feelings of the individual in using SNS. Nevertheless, one will still need to strive to know the person that they are attracted to by exploring more on self-disclosure in order to feel the happiness in their life.

\section{References}

Agbo, A. A., \& Ngwu, C. N. (2017). Aversion to happiness and the experience of happiness: The moderating roles of personality. Personality and Individual Differences, 111, 227-231.

Alfasi, Y. (2019). The grass is always greener on my Friends' profiles: The effect of Facebook social comparison on state self-esteem and depression. Personality and Individual Differences, 147, 111-117.

Amichai, H., \& Ben-Artzi, E. (2003). Loneliness and Internet use. Computers in Human Behaviour, 19, 71-80.

Antheunis, M. L., \& Schouten, A. P. (2011). The effect of Other-Generated and System-Generated Cues on Adolescents' Perceived Attractiveness on Social Network Sites. Journal of ComputerMediated Communication, 16(3), 391-406.

Azzman, T., \& Manaf, M. (2019). Celebrity-Fan Engagement on Instagram and Its Influence on The Perception of Hijab Culture Among Muslim Women in Malaysia. Jurnal Komunikasi: Malaysian Journal of Communication, 35(1), 286-302.

Bakkenbull, L. B., \& Kiefer, S. (2015). Are attractive female tennis players more successful? An empirical analysis. Kyklos, 68(4), 443-458.

Bauman, Z., \& May, T. (2019). Thinking Sociologically. John Wiley \& Sons.

Baumeister, R. F., \& Vohs, K. D. (Eds.). (2007). Encyclopedia of Social Psychology. SAGE.

Bazarova, N., Choi, Y. H., Sosik, S. V., Cosley, D., \& Whitlock, J. (2015, February). Social sharing of emotions on Facebook: Channel differences, satisfaction and replies. In Proceedings of the $18^{\text {th }}$ ACM Conference on Computer Supported Cooperative Work \& Social Computing (pp. 154-164). ACM.

Berrios, R., Totterdell, P., \& Niven, K. (2015). Why do you make us feel good? Correlates and interpersonal consequences of affective presence in speed-dating. European Journal of Personality, 29(1), 72-82.

Burke, M., \& Kraut, R. E. (2016). The Relationship between Facebook Use and Well-Being depends on Communication Type and Tie strength. Journal of Computer-Mediated Communication, 21(4), 265-281.

Cheng, H., \& Furnham, A. (2003). Personality, self-esteem and demographic predictions of happiness and depression. Personality and Individual Differences, 34(6), 921-942.

Clatterbuck, G. (1979). Attributional Confidence and Uncertainty in Initial Interaction. Human Communication Research, 5(2), 147-157.

Clayton, R. B., Nagurney, A., \& Smith, J. R. (2013). Cheating, breakup and divorce: is Facebook use to blame? Cyberpsychology, Behaviour and Social Networking, 16(10), 717-720.

Cronbach, L. (1951). Coefficient alpha and the internal structure of tests. Psychometrika, 16, 297-334.

Crouch, H. (2019). Government and Society in Malaysia. Cornell University Press. 
Daly, M. C., \& Wilson, D. J. (2009). Happiness, unhappiness and suicide: An empirical assessment. Journal of the European Economic Association, 7(2-3), 539-549.

Darbyshire, D., Kirk, C., Wall, H. J., \& Kaye, L. K. (2016). Don't Judge a (Face) Book by its Cover: Exploring judgement accuracy of others' personality on Facebook. Computers in Human Behaviour, 58, 380-387.

Dienlin, T., Masur, P. K., \& Trepte, S. (2017). Reinforcement or Displacement? The Reciprocity of FtF, IM and SNS Communication and Their effect on Loneliness and Life Satisfaction. Journal of Computer-Mediated Communication, 22(2), 71-87.

Dix, A. (2013). A New Era of Courtship. Interpersona, 7(2), 246-259.

Edwards, A., \& Harris, C. (2016). To tweet or 'subtweet'? Impacts of social networking post directness and valence on interpersonal impressions. Computers in Human Behaviour, 63, 304-310.

Eysenck, H. J., \& Eysenck, S. B. (1994). Manual of the Eysenck Personality Questionnaire: (EPQ-R Adult). Educational and Industrial Testing Service.

Feiler, D. C., \& Kleinbaum, A. M. (2015). Popularity, Similarity, and the Network Extraversion Bias. Psychological Science, 26(5), 593-603.

Flesher, D. (2015). Happiness and Time Preference: An Empirical Analysis of Individual Happiness and Information on Intertemporal Choice and Delaying Gratification (Doctoral Dissertation, College of Saint Benedict/Saint John's University).

Francis, L., Brown, L., \& Philipchalk, R. (1992). The development of an abbreviated form of the Revised Eysenck Personality Questionnaire (EPQR-A): Its use among students in England, Canada, the USA, and Australia. Personality and Individual Differences, 13(4), 443-449.

Fredrickson, B. (2003). The value of positive emotions. American Scientist, 91(4), 330-335.

Gambetta, D. (2000). Can We Trust Trust? Trust: Making and Breaking Cooperative Relations, Electronic Edition, Department of Sociology, University of Oxford, 213-237.

Garrison, Y., \& Lee, K. (2017). Meaning in life among Korean college students based on emotionality and tolerance of uncertainty. Personality and Individual Differences, 112, 26-30.

Geisser, S. (1974). A Predictive Approach to the Random effect Model. Biometrika, 61(1), 101-107.

Goodwin, I., Griffin, C., Lyons, A., McCreanor, T., \& Barnes, H. (2016). Precarious popularity: Facebook drinking photos, the attention economy, and the regime of the branded self. Social Media+ Society, 2(1).

Graham, C. (2017). Happiness and economics: insights for policy from the new 'science' of well-being. Journal of Behavioural Economics for Policy, 1(1), 69-72.

Gray, J. S., Ozer, D. J., \& Rosenthal, R. (2017). Goal conflict and psychological well-being: A metaanalysis. Journal of Research in Personality, 66, 27-37.

Gropel, P. (2005). On the theory of life balance: The relation to subjective well-being and the role of self-regulation (Doctoral Dissertation, University of Osnabruck).

Hall, J. A. (2016). Interpreting social-sexual communication. Relational framing theory and socialsexual communication, attraction and intent. Human Communication Research, 42(1), 138-164.

Hampton, K., Goulet, L., Rainie, L., \& Purcell, K. (2011). Social Networking Sites and our lives. Pew Internet \& American Life Project, 16, 1-85.

Hancock, J. T., Toma, C. L., \& Fenner, K. (2008, November). I know something you do not: the use of asymmetric personal information for interpersonal advantage. In Proceedings of the 2008 ACM Conference on Computer supported cooperative work (pp. 413-416). ACM. 
Hertlein, K. M., \& Webster, M. (2008). Technology, relationships and problems: A research synthesis. Journal of Marital and Family Therapy, 34(4), 445-460.

Heisler, J., \& Crabill, S. (2006). Who are "Stinkybug" and "packerfan4"? email pseudonyms and participants' perceptions of demography, productivity, and personality. Journal of ComputerMediated Communication, 12(1), 114-135.

Hong, S., Tandoc, J. E., Kim, E. A., Kim, B., \& Wise, K. (2012). The real you? The role of visual cues and comment congruence in perceptions of social attractiveness from Facebook profiles. Cyberpsychology, Behaviour and Social Networking, 15(7), 339-344.

Horan, S. (2016). Physical/Social Attraction. The International Encyclopedia of Interpersonal Communication. John Wiley \& Sons.

Horrigan, J., Boase, J., Rainie, L., \& Wellman, B. (2006). The Strength of Internet Ties. Pew Research Center: Internet \& Technology. Retrieved August 19, 2014, from https://www.pewinternet.org/2006/01/25 /the-strength-of-internet-ties/

Huang, C. L., Yang, S. C., \& Chen, A. S. (2015). Motivations and gratification in an online game: Relationships among players' self-esteem, self-concept and interpersonal relationships. Social Behaviour and Personality: An International Journal, 43(2), 193-203.

Human, L. J., \& Biesanz, J. C. (2011). Through the looking glass clearly: accuracy and assumed similarity in well-adjusted individuals' first impressions. Journal of Personality and Social Psychology, 100(2), 349-364.

Hu, Y., Wood, J. F., Smith, V., \& Westbrook, N. (2004). Friendships through IM: Examining the Relationship between Instant Messaging and Intimacy. Journal of Computer-Mediated Communication, 10(1),38-48.

Jin, B. (2013). How lonely people use and perceive Facebook. Computers in Human Behaviour, 29(6), 2463-2470.

Kashian, N., Jang, J. W., Shin, S. Y., Dai, Y., \& Walther, J. B. (2017). Self-disclosure and liking in computer-mediated communication. Computers in Human Behaviour, 71, 275-283.

Kerkhof, P., Finkenauer, C., \& Muusses, L. (2011). Relational consequences of compulsive internet use: A longitudinal study among newlyweds. Human Communication Research, 37(2), 147-173.

Lee, E., Ahn, J., \& Kim, Y. J. (2014). Personality traits and self-presentation at Facebook. Personality and Individual Differences, 69, 162-167.

Leist, A. (2013). Social media use of older adults: a mini-review. Gerontology, 59(4), 378-384.

Lundy, B., \& Drouin, M. (2016). From social anxiety to interpersonal connectedness: Relationship building within face-to-face, phone, and instant messaging mediums. Computers in Human Behaviour, 54, 271-277.

Lyubomirsky, S. (2001). Why are some people happier than others? The role of cognitive and motivational processes in well-being. American Psychologist, 56(3), 239.

Markova, G. (2018). Not bad, just unhappy: diminished well-being as a motive for interpersonal deviance. Leadership \& Organization Development Journal, 39(1), 66-81.

McCroskey, J., \& McCain, T. (1974). The Measurement of Interpersonal Attraction. Speech Monographs, 41, 261-266.

Mohammadi, E., Gregory, K. B., Thelwall, M., \& Barahmand, N. (2020). Which health and biomedical topics generate the most Facebook interest and the strongest citation relationships?. Information Processing \& Management, 57(3), 1-29. 
Mrad, M., \& Cui, C. (2017). The Roles of Brand Addiction in Achieving Appearance Esteem and Life Happiness in Fashion Consumption: An Abstract. In Marketing at the Confluence between Entertainment and Analytics (pp. 1269-1270). Springer, Cham.

Neuliep, J. W., \& Grohskopf, E. L. (2000). Uncertainty reduction and communication satisfaction during initial interaction: An initial test and replication of a new axiom. Communication Reports, 13(2), 67-77.

Park, Y. A. (2014). The Influences of Narcissism and Emotional Self-Disclosure on the Depression and Happiness Levels of High School Students. Korean Journal of Child Studies, 35(6), 79-92.

Pena, J., \& Brody, N. (2014). Intentions to hide and unfriend Facebook connections based on perceptions of sender attractiveness and status updates. Computers in Human Behaviour, 31, 143-150.

Peterson, C., Park, N., \& Seligman, M. E. (2005). Orientations to happiness and life satisfaction: The full life versus the empty life. Journal of Happiness Studies, 6(1), 25-41.

Pounders, K., Kowalczyk, C., \& Stowers, K. (2016). Insight into the motivation of selfie postings: impression management and self-esteem. European Journal of Marketing, 50(9/10), 18791892.

Ranjbartabar, H., Richards, D., Bilgin, A., \& Kutay, C. (2019). First Impressions Count! The Role of the Human's Emotional State on Rapport Established with an Empathic versus Neutral Virtual Therapist. IEEE Transactions on Affective Computing.

Robards, J. (2014). Digital traces of the persona through ten years of Facebook. Journal of Media and Culture, 17(3), 1.

Santor, D. A., Messervey, D., \& Kusumakar, V. (2000). Measuring peer pressure, popularity and conformity in adolescent boys and girls: Predicting school performance, sexual attitudes and substance abuse. Journal of Youth and Adolescence, 29(2), 163-182.

Scheibe, K. P., \& Gupta, M. (2017). The Effect of Socializing via Computer-mediated Communication on the Relationship between Organizational Culture and Organizational Creativity. Communications of the Association for Information Systems, 40(1), 13-24.

Scott, G. G. (2014). More than friends: Popularity on Facebook and its role in impression formation. Journal of Computer-Mediated Communication, 19(3), 358-372.

Sharkawi, S., Rahim, A. R. A., \& Dahalan, A. N. (2013). Relationship between Person Organization Fit, Psychological Contract Violation on Counterproductive Work Behaviour. International Journal of Business and Social Science, 4(4), 173-183.

Sheldon, P. (2009). I'll poke you. You'll poke me! Self-disclosure, Social Attraction, predictability and trust as important predictors of Facebook relationships. Cyberpsychology: Journal of Psychosocial Research on Cyberspace, 3(2), 67-75.

Sneade, M., \& Furnham, A. (2016). Hand grip strength and self-perceptions of physical attractiveness and psychological well-being. Evolutionary Psychological Science, 2(2), 123-128.

Sprecher, S., Treger, S., \& Wondra, J. (2013). effect of self-disclosure role on liking, closeness and other impressions in get-acquainted interactions. Journal of Social and Personal Relationships, 30(4), 497-514.

Spiegelhalter, D. (2017). Risk and uncertainty communication. Annual Review of Statistics and Its Application, 4, 31-60. 
Steel, P., \& Ones, D. S. (2002). Personality and happiness: A national-level analysis. Journal of Personality and Social Psychology, 83(3), 767-781.

Suwanphrom, S. (2016). Managing strategies of professional football clubs in Thailand for increasing fan clubs. HRD Journal, 6(2), 6-18.

Tiedens, L. Z., \& Linton, S. (2001). Judgment under emotional certainty and uncertainty: the effect of specific emotions on information processing. Journal of Personality and Social Psychology, 81(6), 973.

Tifferet, S., \& Vilnai-Yavetz, I. (2014). Gender differences on Facebook self-presentation: An international randomized study. Computers in Human Behaviour, 35, 388-399.

Wang, R., Liu, H., Jiang, J., \& Song, Y. (2017). Will materialism lead to happiness? A longitudinal analysis of the mediating role of psychological needs satisfaction. Personality and Individual Differences, 105, 312-317.

Williams, D., Kennedy, T. L., \& Moore, R. J. (2011). Behind the avatar: The patterns, practices and functions of role-playing in MMOs. Games and Culture, 6(2), 171-200.

Winter, S., Haferkamp, N., Stock, Y., \& Kramer, N. C. (2011). The Digital Quest for Love - The Role of Relationship Status in Self-Presentation on Social Networking Sites. Journal of Psychological Research in Cyberspace, 5(2).

Wolfe, W. L., \& Patterson, K. (2017). Comparison of a gratitude-based and cognitive restructuring intervention for body dissatisfaction and dysfunctional eating behavior in college women. Eating Disorders, 25(4), 330-344.

Wong, K. (2013). Partial Least Squares Structural Equation Modeling (PLS-SEM) Techniques using SmartPLS. Marketing Bulletin, 24(1), 1-32.

Woo, J., \& Jungryum, K. (2016). Measuring Attractiveness of Celebrities. Ewha Journal of Social Sciences, 32(2).

Wu, T., \& Zheng, Y. (2019). Is Impression Management Through Status Updates Successful? Metaaccuracy and Judgment Accuracy of Big Five Personality Traits Based on Status Updates from Social Network Sites in China. Frontiers in Psychology, 10, 1-9.

Zelenski, J. M., Murphy, S. A., \& Jenkins, D. A. (2008). The happy-productive worker thesis revisited. Journal of Happiness Studies, 9, 521-537.

Zhang, Y., \& Ji, Q. (2003). Facial expression understanding in image sequences using dynamic and active visual information fusion. In Computer Vision, 2003. Proceedings. Ninth IEEE International Conference on (pp. 1297-1304). IEEE.

Zywica, J., \& Danowski, J. (2008). The faces of Facebookers: Investigating social enhancement and social compensation hypotheses; predicting Facebook ${ }^{\mathrm{TM}}$ and offline popularity from sociability and self-esteem and mapping the meanings of popularity with semantic networks. Journal of Computer-Mediated Communication, 14(1), 1-34. 